\title{
Application of GGBFS and Bentonite to Auto-Healing Cracks of Cement Paste
}

\author{
J J Ekaputri ${ }^{1}$, M S Anam ${ }^{2}$, Y Luan ${ }^{3}$, C Fujiyama ${ }^{4}$, N Chijiwa ${ }^{5}$, D H E Setiamarga ${ }^{6}$ \\ ${ }^{I}$ Civil Engineering Department, Institut Teknologi Sepuluh Nopember, Surabaya, Indonesia \\ ${ }^{2} P T$ Wijaya Karya, Jakarta, Indonesia \\ ${ }^{3}$ Department of Civil and Environmental Engineering, Saitama University, Japan \\ ${ }^{4}$ Department of Civil and Environmental Engineering, Hosei University, Tokyo, Japan \\ ${ }^{5}$ Department of Civil and Environmental Engineering, Tokyo Institute of Technology, Japan \\ ${ }^{6}$ National Institute of Technology, Materials Science Department, Wakayama, Japan \\ E-mail: januartije@gmail.com
}

(Received: March 15 $5^{\text {th }}, 2018$; Accepted: April 27 $7^{\text {th }}, 2018$ )

\begin{abstract}
Cracks are caused by many factors. Shrinkage and external loading are the most common reason. It becomes a problem when the ingression of aggressive and harmful substance penetrates to the concrete gap. This problem reduces the durability of the structures. It is well known that self - healing of cracks significantly improves the durability of the concrete structure. This paper presents self-healing cracks of cement paste containing bentonite associated with ground granulated blast furnace slag. The selfhealing properties were evaluated with four parameters: crack width on the surface, crack depth, tensile strength recovery, and flexural recovery. In combination with microscopic observation, a healing process over time is also performed. The results show that bentonite improves the healing properties, in terms of surface crack width and crack depth. On the other hand, GGBFS could also improve the healing process, in terms of crack depth, direst tensile recovery, and flexural stiffness recovery. Carbonation reaction is believed as the main mechanism, which contributes the self-healing process as well as the continuous hydration progress.
\end{abstract}

Keywords: Cracks, self-healing, concrete, durability, bentonite, blast furnace slag

\section{INTRODUCTION}

Crack is one of the damage on the concrete structure which is caused by many factors such as shrinkage, nonuniform settlement or displacement, thermal different, chemical reaction, improper structural design, improper construction method, or overload case [1]. Since the probability of crack occurrence is very high, repairing is required before the crack propagate widely. A late action may lead to the decrease the strength, concrete deterioration, corrosion of concrete reinforcement, and reduce the durability of structures [2].

Self-healing concrete approach was widely studied by many researchers to solve crack problems. Some mechanisms such as swelling and recrystallization mechanism [3], carbonation reaction, progress of hydration products [4], bacteria metabolism to produce $\mathrm{CaCO}_{3}$ [5], low-rate of pozzolanic reaction [6] are commonly mechanisms that have been proven able to generate selfhealing properties. Application of some clay minerals containing montmorillonite is potential material for self-healing concrete [3], [7], [8]. Closing the gap is caused by high ion-exchange capacity of montmorillonite, which can contribute swelling mechanism [9]. Crack of concrete containing 5\% geomaterial has high self-healing efficiency, compared to the normal concrete by using immersion water curing. It is due to diffusion of $\mathrm{Al}^{3+}$ ion and $\mathrm{Si}^{4+}$ Ion [1]. Furthermore, nano-clay/geomaterial also can be used as inner water retaining supply. This inner water has some 
advantage for carbonation reaction and hydration reaction to produce self-healing properties. Crack of concrete containing small portion of nano-clay is found to have greater deflection capacity after cracking, as compared to the normal concrete [10].

Not all the clinker cement is hydrated in early age, because some unhydrated particles are available in the concrete matrix [10]. If the crack occurs, the particles react with water passing inside the gap. The result of this reaction is C-S-H gel, which blocks the crack. Application of some byproduct materials, such as Blast Furnace Slag (BFS) is also a potential material for selfhealing concrete, because of their latent hydraulic properties. BFS has slow hydration reaction, compared to clinker cement hydration. BFS has also latent hydraulic properties, its mean that besides using water as reactant, hydration reaction of BFS needs high $\mathrm{pH}$ to activate its particles. High $\mathrm{Ca}(\mathrm{OH})_{2}$ concentration producing high alkali to accelerate hydration reaction of BFS particles [11]. High replacement of BFS provides unhydrated clinker particle remaining in the concrete matrix [12]. If the crack occurs, this particle reacts with available water in the crack's gap. The result of this reaction is $\mathrm{C}-\mathrm{S}-\mathrm{H}$ gel which can fill up the crack.

This paper focuses on the application of bentonite and ground granulated blast furnace slag (GGBFS) as cementitious material to self-healing mechanism of paste to observe the surface crack width, depth of crack, and recovery of tensile and regain of flexural strength.

\section{EXPERIMENTAL METHOD}

\section{Materials}

The cementitious material consisted of ordinary Portland cement (OPC), ground granulated blast furnace slag (GGBFS), and bentonite (BNT). The physical and chemical properties of raw material are shown in Table 1.

Table 1. Properties of Materials

\begin{tabular}{|c|c|c|c|c|}
\hline Properties & Unit & OPC & BNT & $\begin{array}{c}\text { GGBF } \\
\text { S }\end{array}$ \\
\hline \multicolumn{5}{|c|}{ Physical Properties } \\
\hline - Unit weight & $\mathrm{gr} / \mathrm{cm}^{3}$ & 1.21 & 0.87 & 0.94 \\
\hline $\begin{array}{l}\text { - Specific } \\
\text { Gravity }\end{array}$ & - & 3.14 & 2.57 & 2.78 \\
\hline - Max diameter & $\mathrm{Um}$ & - & 400 & 125 \\
\hline - passing 75 um & $\%$ & - & 81.9 & 92.6 \\
\hline $\begin{array}{l}\text { - Specific } \\
\text { Surface Area }\end{array}$ & $\mathrm{cm}^{2} / \mathrm{gr}$ & - & 1996 & 2934 \\
\hline \multicolumn{5}{|c|}{ Mechanical Properties } \\
\hline $\begin{array}{l}\text { - Strength } \\
\text { Activity Index }\end{array}$ & $\begin{array}{c}\text { MPa } \\
(-)\end{array}$ & $\begin{array}{c}23.9 \\
(1.00) \\
\end{array}$ & $\begin{array}{c}3.75 \\
(0.15) \\
\end{array}$ & $\begin{array}{r}17.9 \\
(0.73) \\
\end{array}$ \\
\hline \multicolumn{5}{|c|}{ Chemical Properties } \\
\hline $\mathrm{SiO}_{2}$ & $\% \mathrm{wt}$ & N/A & 56.13 & 36.33 \\
\hline $\mathrm{Al}_{2} \mathrm{O}_{3}$ & $\% \mathrm{wt}$ & N/A & 21.57 & 16.04 \\
\hline $\mathrm{Fe}_{2} \mathrm{O}_{3}$ & $\% \mathrm{wt}$ & N/A & 5.31 & 0.95 \\
\hline $\mathrm{CaO}$ & $\% \mathrm{wt}$ & N/A & 0.58 & 34.59 \\
\hline $\mathrm{K}_{2} \mathrm{O}$ & $\% \mathrm{wt}$ & N/A & 1.29 & 0.46 \\
\hline $\mathrm{MgO}$ & $\% \mathrm{wt}$ & N/A & 0.95 & 9.24 \\
\hline $\mathrm{Na}_{2} \mathrm{O}$ & $\% \mathrm{wt}$ & N/A & 0.23 & 0.31 \\
\hline Others & $\% \mathrm{wt}$ & N/A & 0.90 & 1.48 \\
\hline
\end{tabular}

To compare the mixture effect to self-healing ability of the paste, four mixtures were composed with different binders: (1) OPC; (2) OPC containing GGBFS; (3) OPC containing BNT; and (4) OPC containing both GGBFS and BNT. Detail composition of the binders is listed 
in Table 2. To control the quality of results, two identical specimens were composed. Dogbonelike specimens were also prepared for direct tensile recovery and visual crack closure. Three identical cracked prisms for each mixture were analyzed for visual crack closure, depth of crack, and flexural regain. Flow diameter of cement paste on flow table test was fix at $22 \mathrm{~mm}$ affect some different in the water to binder ratio for each composition.

Tabel 2. Mix composition

\begin{tabular}{ccccc}
\hline Code & $\begin{array}{c}\% \\
\text { OPC }\end{array}$ & \% GGBFS $\%$ BNT & w/b \\
\hline B0FS00 & $100 \%$ & - & - & 0.342 \\
B5FS00 & $70 \%$ & $30 \%$ & - & 0.421 \\
B0FS30 & $95 \%$ & - & $5 \%$ & 0.355 \\
B5FS30 & $65 \%$ & $30 \%$ & $5 \%$ & 0.428 \\
\hline
\end{tabular}

\section{Introducing Artificial Crack}

To create an artificial crack, three methods were performed. Dog bone specimens were subjected to direct tensile test until the specimen split in two parts, and then the two parts were connected become one specimen and held with dogbone specimen holder. Prism specimens were subjected to the four-point bending test until the crack occurred. Cylindrical specimens were subjected to splitting test to create artificial crack. Crack widths of all specimens were controlled to be less than $0.3 \mathrm{~mm}$ which is the maximum crack width allowed by ACI 224R-01 [1].

\section{Testing Method}

Flow table test was performed according to ASTM C 230 -08 [13]. Flow table test was conducted to achieve water per binder ratio (w/b) of the specimen series for equivalent consistency. A reactivity test ASTM C 593-11 [14] was conducted for BNT, GGBFS, and OPC to obtain the strength activity index (SAI). This reactivity test was conducted by using hydrated lime $\left[\mathrm{Ca}(\mathrm{OH})_{2}\right]$ as a reagent. SAI was calculated with the compressive strength ratio of the mortar to the strength of OPC mortar at seven days.

SAI of each composition is presented in Fig 1. SAI index (SAI) of bentonite is 0.15 which is the smallest. Although bentonite consist of $56.13 \%$ of $\mathrm{SiO}_{2}$, it is dominantly structured as crystalline minerals. On the other hand, the strength activity index of GGBFS is 0.73 which is smaller than OPC but greater than bentonite. This shows that GGBFS used in the mixture belongs to amorphous minerals.

Microscopic observation was conducted with camera having 900 magnification scale. About 15 representative crack locations of each mixture were selected. The points were signed by using water resistant marker to make a constant observation. This microscopic observation was conducted at three to 56 days after initial crack was applied. Ultrasonic pulse velocity test was performed according to ASTM C 597 - 16 [15] to calculate the crack depth during observation. A four-point flexural test according to ASTM C 78-18 [16] were conducted to determine mechanical recovery, in accord with the flexural beams. The beam size is $15 \mathrm{~cm}$ x $15 \mathrm{~cm}$ x $60 \mathrm{~cm}$ as shown in Fig 2. Direct tensile test (CRD - C 260 - 01) [17] was conducted to determine mechanical regain, with respect to tensile strength recovery. Both flexural and tensile test were conducted for all 28 day specimens. All specimens were kept in moist curing condition in room temperature during the observation. $\mathrm{pH}$ measurement was conducted to identify carbonation process occur during healing process. Sample was selected from the precipitated materials inside the gap and compared with sample from the paste. $\mathrm{pH}$ measurement and X-Ray diffraction test were performed to analysed the samples. 


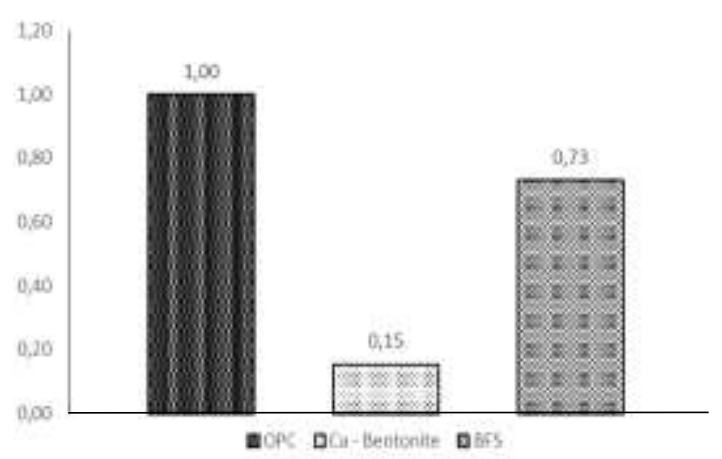

Fig 1. SAI of OPC, BNT and GGBFS

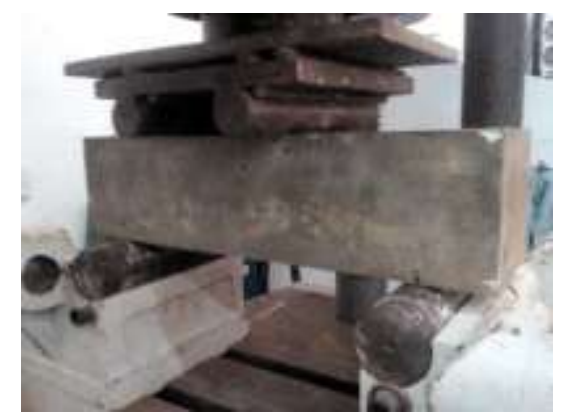

Fig 2. Bending Test

\section{RESULTS AND DISCUSSIONS}

\section{Slump Flow of Cement Paste Mixture}

Utilization of bentonite and GGBFS as cement replacement can decrease the flow ability of the cement mixture with a constant water/binder ratio. Fig 3 describes the graphics of B5FS00, B0FS30, and B5FS30 are plotted under the line of control mixture (B0FS00). However, utilization bentonite as $5 \%$ of cement replacement decreases flow ability much more than the application of GGBFS in the mixture. Decreasing flow ability by bentonite is influenced by montmorillonite content of bentonite, which adsorbs water and swell [18]. Decreasing flow ability by GGBFS replacement is expectedly influenced by micro shape of GGBFS particles which has more specific surface area [19-21].

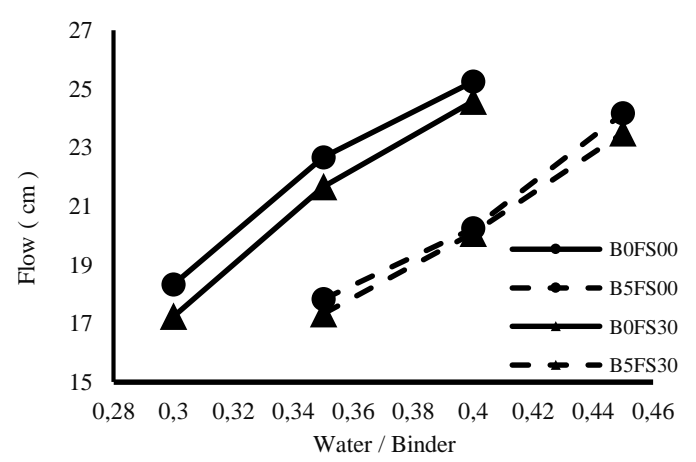

\section{Microscopic Observation}

Fig 3. Flowability of the cement paste mixture

The image of the crack closure over time is shown in Fig 4. The influence of GGBFS to self healing process is noticeable by crack closing rate and the healing material closing the crack's 
surface. Utilization of GGBFS as autogenous healing material shows slower closing rate, compared to others which almost closed completely at one week.

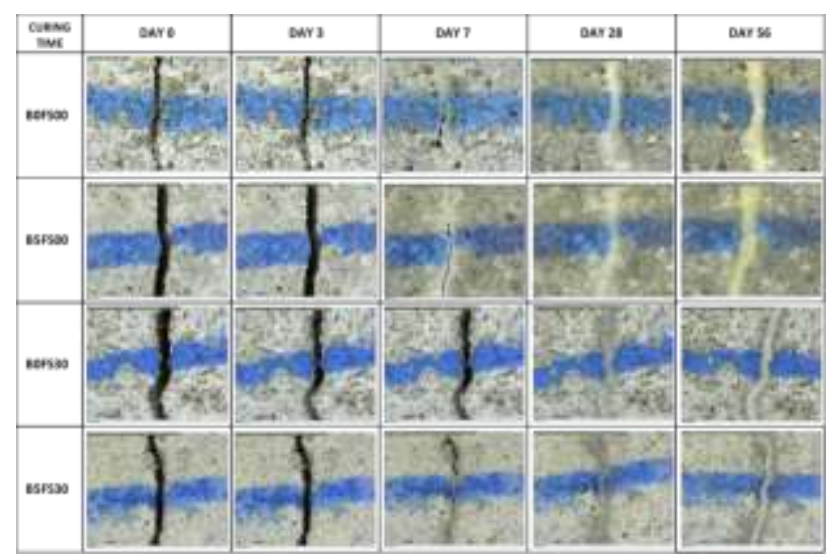

Fig 4. Visual observation of crack widht over time

According to Titleboom et al [4], Ekaputri et al [19-21], and Nasir et al [22], materials containing BFS and pozzolans have slower reaction in the early time and reacts at the later age. This is the reason why at 28 days, the crack of all speciments were closed imperfectly. Control mixture (BOFS00) showed self healing occurred as it produced $\mathrm{Ca}(\mathrm{OH})_{2}$ to react with $\mathrm{CO}_{2}$ to form $\mathrm{CaCO}_{3}$ precipitated in the crack's gap.

As shown in Fig 5 to Fig 8, all mixtures as ability of self-healing. All cracks with different initial crack width decreased until 56 day-curing periode except specimens using GGBFS which has initial crack width greather than $0.30 \mathrm{~mm}$. After 28 age days, crack of specimens containing bentonite (B5S00) almost closed perfectly.

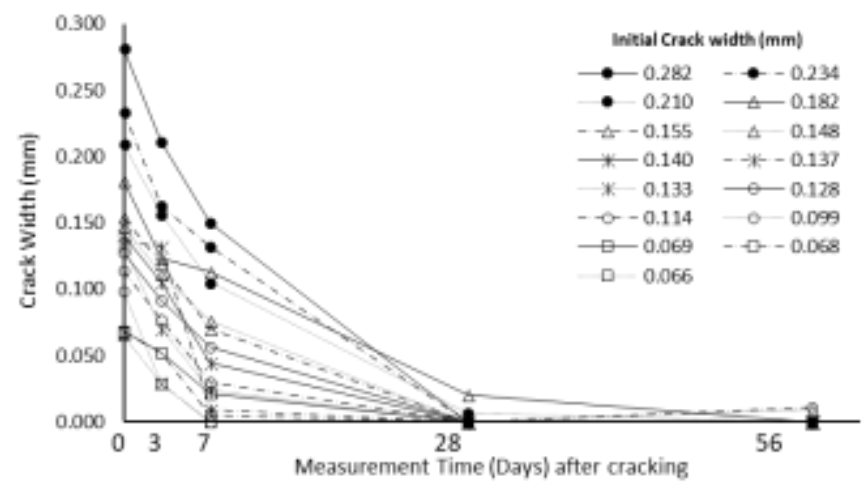

Fig 5. Cracks closure for BOFSO0

At the same time, crack of specimens with GGBFS closed incompletely (plotted data inside red dash circle in Fig 7 and Fig 8). This fact is inline with microscopic picture in Fig. 4, that bentonite is the best material for decreasing the crack width. This is caused by additional $\mathrm{Ca}^{2+}$ ion from montmorillonite increasing precipitation of $\mathrm{CaCO}_{3}$ crystal. Dissolution of bentonite in $\mathrm{Ca}(\mathrm{OH})_{2}$ could increase amount of $\mathrm{Ca}^{2+}$ ion [23] as explained with chemical reaction in equation (1). 


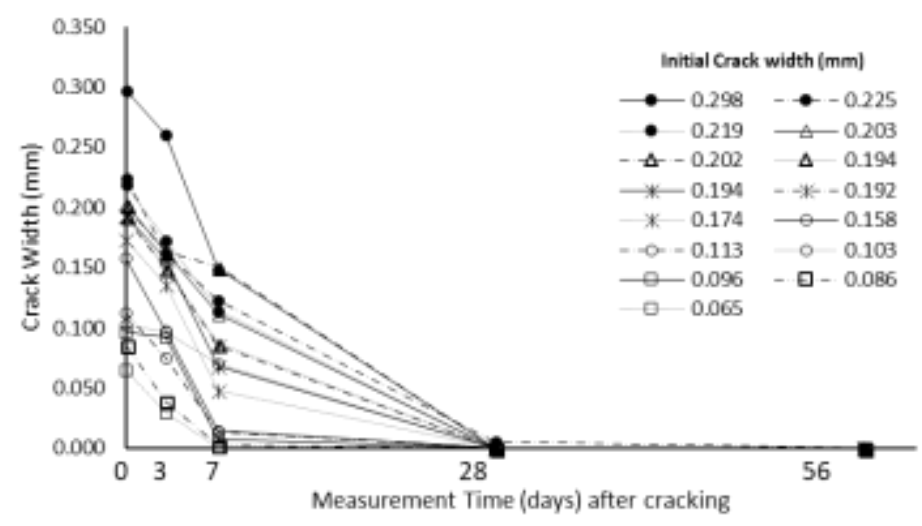

Fig 6. Cracks closure for B5FS00

$$
\begin{aligned}
& \underset{\text { (bentonite) }}{\mathrm{Ca}_{0.165} \mathrm{Al}_{1.67} \mathrm{Si}_{4} \mathrm{O}_{10}(\mathrm{OH})_{2}+2.34 \mathrm{Ca}(\mathrm{OH})_{2}}+2 \mathrm{H}_{2} \mathrm{O} \\
& \rightarrow 2.505 \mathrm{Ca}^{2+}+1.67 \mathrm{Al}(\mathrm{OH})^{4-}+4 \mathrm{HSiO}^{3-}
\end{aligned}
$$

Mixtures containing GGBFS showed the lowest healing rate at 28 age days. It was mainly caused by slow hidration rate of GGBFS particle [4]. It is in agreement with the result reported by Oliver [24], that portland cement with 50\% slag replacement has the tendency to a slower selfhealing in the early age than the reference mixtures with $100 \%$ portland cement. Beside that, it was found that GGBFS generally could only close small cracks especially for initial crack which was less than $0.2 \mathrm{~mm}$. When the initial crack width greather than $0.2 \mathrm{~mm}$, the healing rate became lower.

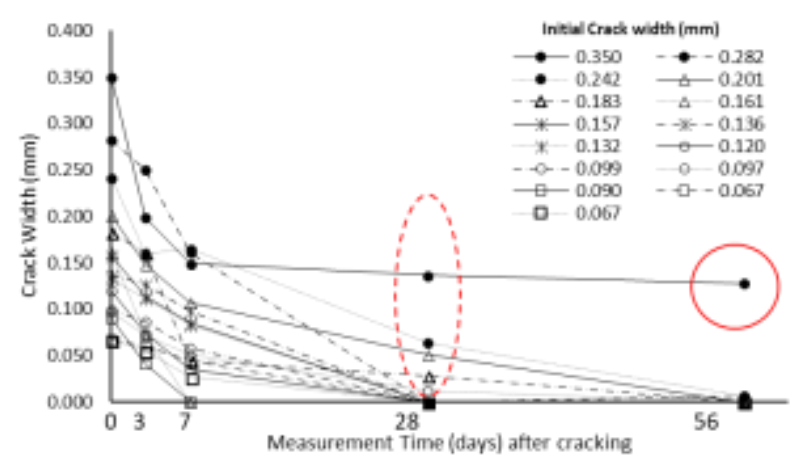

Fig 7. Cracks closure for B0FS30

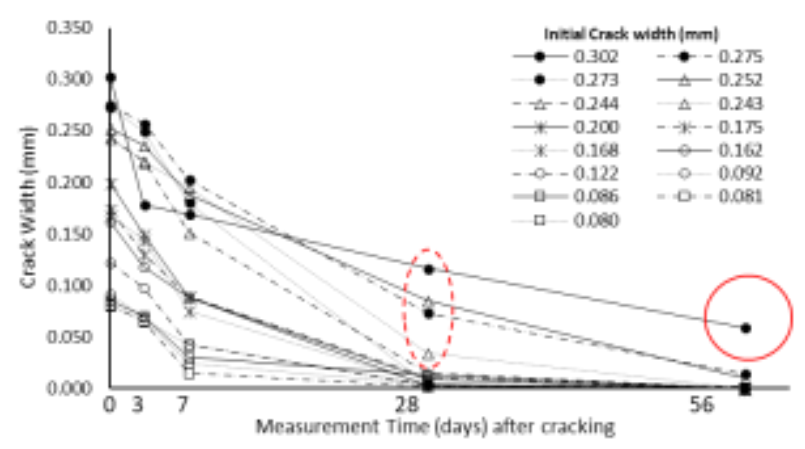

Fig 8. Cracks closure for B5FS30 


\section{Crack Depth}

Alongside surface crack observation, self-healing process was also evaluated by measuring crack depth. The healing process was evaluated by using $\alpha$ index, where $\alpha$ index is a ratio of decreasing crack depth to the initial crack depth. The influence of mixtures (bentonite and GGBFS) to $\alpha_{\text {index }}$ is shown in Fig 9.

Utilization GGBFS as cement replacement shows higher rate of healing, as compared with others. It can be compared clearly that specimens B0FS30 and B5FS30 are plotted far above the other specimens. In addition, the presence of bentonite in the mixture increase the better healing rate. However, the maximum $\alpha_{\text {index }}$ is 0.35 . It indicates that some cracks were left un-closed.

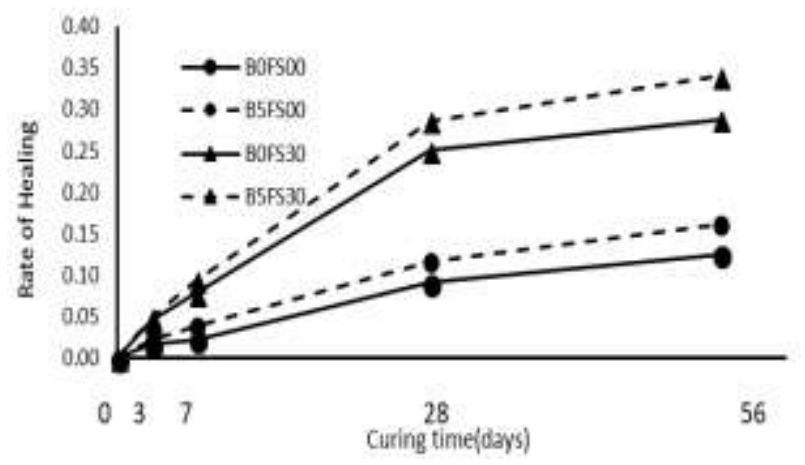

Fig 9. Rate of healing with reference to crack depth

The rate of healing is also influenced by water to binder ratio of each mixtures as shown in Fig 10. The healing rate of mixtures with high water to binder ratio representing by GGBS specimens show higher healing rate. The formation of CSH as healing material is depending on the chemical reaction where the water is required. Therefore, latent hydraulic process in specimens containing GGBFS accelerated rate of healing with sufficient water in the mixture.

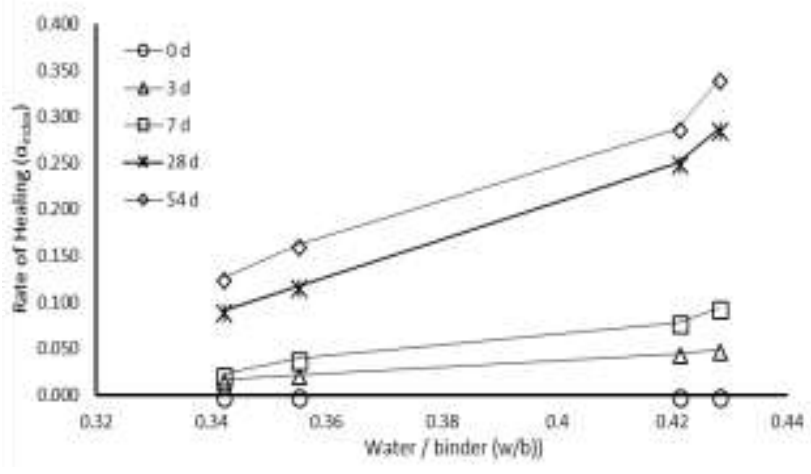

Fig 10. Effect of w/b to the rate of healing

\section{Tensile Strength Recovery}

The result of tensile strength of initial strength and after healing at 56 days are in Fig $\mathbf{1 1}$ and Fig 12 respectively. The recovery of tensile strength of specimens containing bentonite is lower than others. Apparently, the tensile strength of specimens containing GGBFS recovered faster than B0FS00 and B5FS00. Since bentonite contains crystalline materials, it has the lowest contribution to regain the strength by the formation of calcium silicate hydrate $(\mathrm{C}-\mathrm{S}-\mathrm{H})$ resulted from cement hydration. Decreasing amount of C-S-H can decrease mechanical strength of the cement mixtures. 


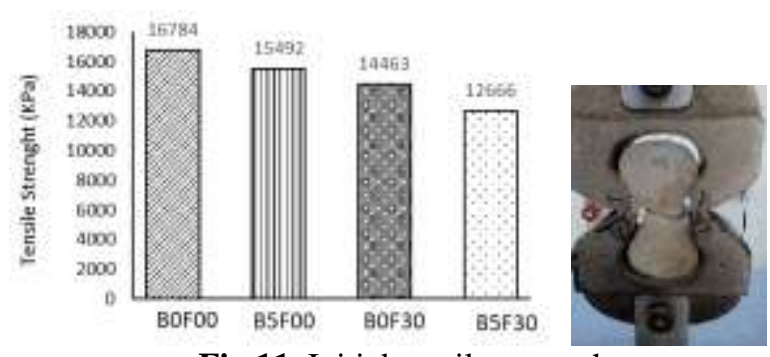

Fig 11. Initial tensile strength

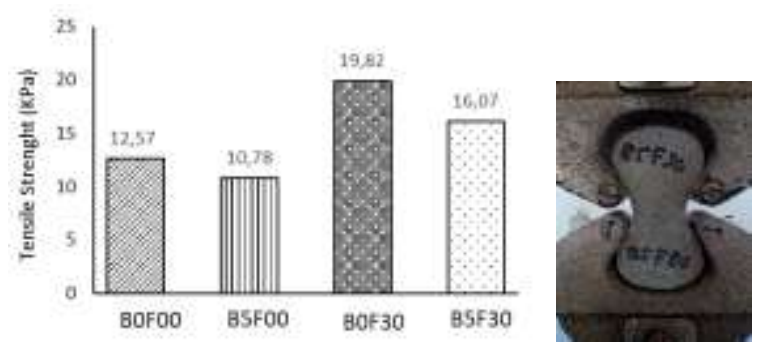

Fig 12. Tensile strength after healing process at 56 days

It is different from specimens containing GGBFS. GGBFS contributes tensile strength recovery although its initial strength is lower. The reversed condition was shown during healing process. Its latent hydraulic properties activated by $\mathrm{Ca}(\mathrm{OH})_{2}$ resulted unreacted particle of GGBFS still available in the cement matrix. Beside latent hydraulic properties of GGBFS, it is also caused by slow reaction properties of GGBFS. The same phenomenon was reported by materials containing pozzolans. At the early age, hydration reaction of these materials is very low, it occurs significantly at the later age $[8,25]$.

\section{Flexural Recovery}

The results of all specimens are shown in Fig 13. It shows similar trend of all mixtures after healing (A) process and before healing process (B). However, there is slightly different stiffness of before and after healing. The decreases in flexural stiffness for all beams were caused by the remain of un-closed cracks. It has been explained that the maximum rates of healing of all mixtures are around 0.35, in terms of crack depth. This open gap reduces the effective depth of beams causing the inertia of moment also decreases. As a consequently, the flexural stiffness of all mixtures after healing process (A) are lower than before healing process (B). However, specimen B0FS30 shows higher flexural stiffness after healing process, compared to control specimen. It has the similar trend to tensile recovery results which shows higher tensile strength recovery after healing.

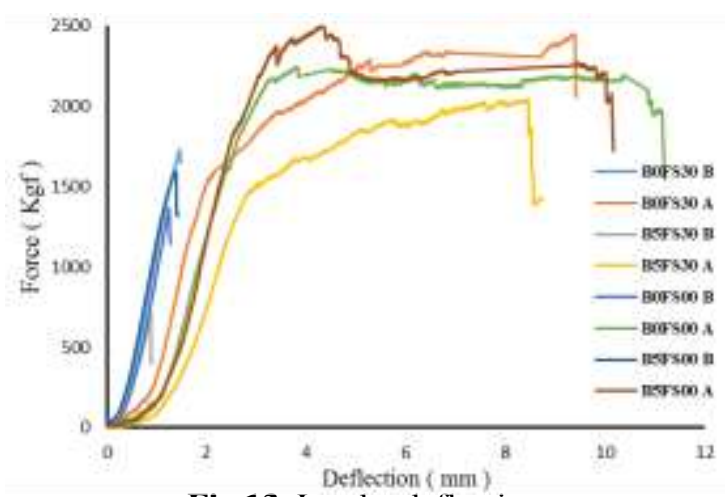

Fig 13. Load - deflection curve 


\section{pH Measurement}

Alkalinity is also measured for different mixtures, both inside the gap and the paste. This measurement is very important to analyze the carbonation reaction during healing process. The measurement is presented in Fig. 14.

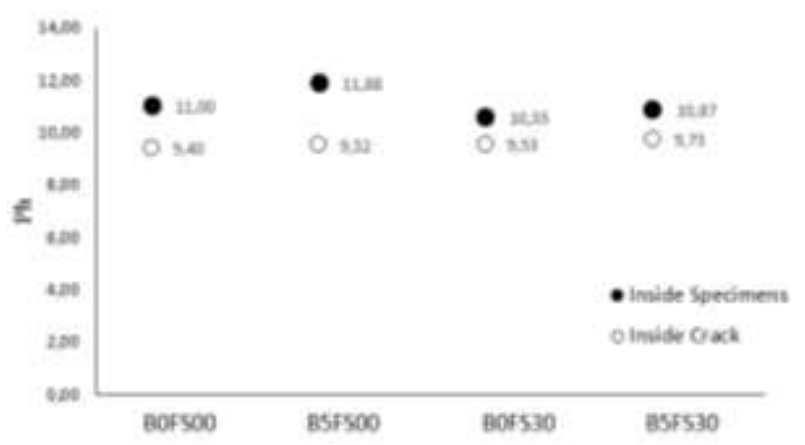

Figure 14. $\mathrm{pH}$ of each composition

The specimens without GGBFS show the highest $\mathrm{pH}$. It indicated that the sample contains alkalinity provided by $\mathrm{Ca}(\mathrm{OH})_{2}$ which is soluble. This alkali activated latent hydraulic properties of GGBFS resulted in lower $\mathrm{pH}$ in other specimens. In addition, after healing process, $\mathrm{pH}$ inside the gap of each specimen is much lower than their initial $\mathrm{pH}$. It is caused by carbonation reaction between $\mathrm{Ca}(\mathrm{OH})_{2}$ and $\mathrm{CO}_{2}$ to form $\mathrm{CaCO}_{3}$. The more precipitated of $\mathrm{CaCO}_{3}$ formed in the gap, the amount of $\mathrm{Ca}(\mathrm{OH})_{2}$ reduces to decrease the $\mathrm{pH}$. At the same time, specimens containing GGBFS showed higher $\mathrm{pH}$ of healing material. It indicates that carbonation is prevented by GGBFS application. On the other hand, bentonite utilization as cement replacement increased the $\mathrm{pH}$.

X-Ray Diffraction testing was conducted to identify mineral closing crack for different mixtures. The result is presented in Fig 15. Minerals obtained from the gap inside the crack is dominated by calcite $\left(\mathrm{CaCO}_{3}\right)$ and portlandite $\left(\mathrm{Ca}(\mathrm{OH})_{2}\right)$. Beside calcite and portlandite, gypsum, bassanite, and magnesite were also present inside of crack for all mixtures, but in a very small portion. Replacement cement with GGBFS formed calcite mainly by chemical reaction to reduce the portlandite $\left(\mathrm{Ca}(\mathrm{OH})_{2}\right)$. On the other hand, portlandite content was found higher in specimens without GGBFS. The calcite was precipitetad as a product of reaction beetwen portlandite and disolved $\mathrm{CO}_{2}$ in the crack's gap.

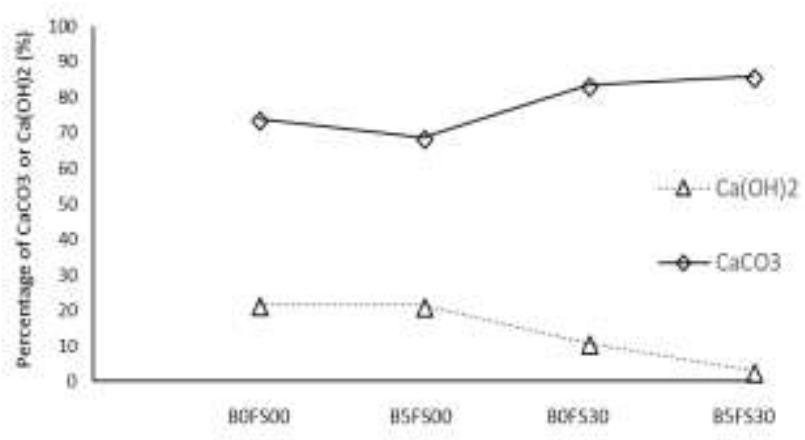

Fig. 15. Minerals identification in the crack healing area 


\section{CONCLUSIONS}

The influence of bentonite and blast furnace slag to the self-healing of cementitious materials was investigated. The healing properties are evaluated using four parameters, including surface crack width, crack depth, direct tensile regain, and flexural recovery. With integrated microscopic and chemical observation, the healing process was assessed for 56 days. The results can be concluded as follows:

1. Application of bentonite is a benefit to close up the crack width on the surface. At the same time, the presence of GGBFS decreased the crack depth which accelerated the closing rate more than the control specimens.

2. Application of GGBFS resulted in higher tensile strength regained after cracking compared to other mixtures, where bentonite showed lower strength regained after cracking.

3. During healing process, all mixtures showed lower flexural stiffness than the initial stiffness. However, application of GGBFS resulted in the highest stiffness. Decreasing of flexural stiffness was caused by cracks were remained unhealed resulted in the decrease of the beam's moment of inertia.

4. XRD analysis and $\mathrm{pH}$ measurement indicated that self-healing process was influenced significantly by carbonation reaction for control specimen. However, GGBFS contributes more to the production of $\mathrm{CSH}$ at the later age rather than carbonation reaction.

\section{REFERENCES}

[1] ACI 224R - 01. Control of Cracking in Concrete Structure. Newyork: American Concrete Institute

[2] Hartt, William H. 2009. Effect of concrete crack width on corrotion of embedded reinforcement. Research Report, Florida: Morada Court Boca Raton.

[3] Ahn, Tae-Ho, and Toshiharu Kishi. 2010. "Crack Self-healing Behavior of Cementitious Composites Incorporating Various Mineral Admixtures." Journal of Advanced Concrete Technology (Japan Concrete Institute) 8: 171 - 186.

[4] Tittelboom, Kim Van, Elke Gruyaert, Hubert Rahier, and Nele De Belie. 2012. "Influence of mix composition on the extent of autogenous crack healing by continued hydration or calcium carbonat formation." Construction and building material (Elsevier) 37: 349 - 359.

[5] Jonkers, Henk M, and Erik Schlangen. 2009. "A Two Component Bacteria-Based Self Healing Concrete." Edited by Alexander et al. Concrete Repair, Rehabilitation and Retrofitting II (Taylor \& Francis Group).

[6] Hung, Vu Viet, and Toshiharu Kishi. 2013. "Water - tightness performance of crack-self healing concrete incorporating various types of granule of supplementary cementitious materials and/or Portland cement and other additives." Third International Conference on Suistainable Construction Materials and Technologies. Kyoto: Japan Concrete Institute

[7] Jiang, Zhengwu, Wenting Li, and Zhengcheng Yuan. 2015. "Influence of mineral additive and environmental condition on the self healing capabilities of the cementious materials." Cement and Concrete Composites (Elsevier) 57: 116 - 127.

[8] Lothenbach, B., G. Le Saout, M. Ben Haha, R. Figi, and E. Wieland. 2012. "Hydration of a low-alkali CEM III/B-SIO2 cement (LAC)." Cement and Concrete Research (Elesevier) 42: 410 - 423.

[9] Muurinen, Arto. 2011. Measurement on cation exchange capacity of bentonite in the long-term test of buffer material $(L O T)$. Working Report, Eurajoki: Posiva OY.

[10] Qian, S.Z, J Zhou, and E. Schlangen. 2010. "Influence of curing condition and precracking time on self healing behavior of engineered cementious composites." Cement and concrete composites (Elsevier) 32: $686-693$.

[11] Huang, Haoliang, and Guang Ye. 2012. "Simulation of self-healing by further hydration in cementitious materials." Cement and Concrete Composites (Elsevier) 34: 460 - 467.

[12] Lv, Zhong, and Huisu Chen. 2012. "Modeling of self healing efficiency for crack due to unhydrated cement nuclei in hardened cement paste." Procedia Engineering (Elesevier) 27: 281 - 290. 
[13] ASTM C230-08 Standard Specification for Flow Table for Use in Tests of Hydraulic Cement, Flow and flow rate, 2008

[14] C593 - 11 Standard Specification for Fly Ash and Other Pozzolans for Use With Lime for Soil Stabilization, 2011

[15] ASTM C 597 - 16 Standard Test Method for Pulse Velocity Through Concrete, 2016

[16] ASTM C 78-18 Standard Test Method for Flexural Strength of Concrete (Using Simple Beam with Third-Point Loading), 2018

[17] CRD-C260-01, 2001. Standard Test Mothod for Tensile Strength of Hydraulic Cement Mortars, 2001, Handbook For Concrete and Cement, National Institute of Building Sciences

[18] Lim, C. S., Gomes, C. \& Kadir, M. Z. A. A., 2013. Characterizing of Bentonite with Chemical, Physical and Electrical Perspectives for Improvement of Electrical Grounding Systems. International Journal of Electrochemical Science, Vol.8,pp. 11429 - 11447.

[19] Januarti Jaya Ekaputri, Koichi Maekawa, Tetsuya Ishida, 2016. Experimental Study on Internal RH of BFS Mortars at Early Age, Materials Science Forum, ISSN web: 1662-9752, ISSN CD 1662-9760 ISSN web, ISSN print: 0255-5476, ISBN: 978-3-0357-1020-5, Vol. 857, pp 305-310 doi:10.4028/www.scientific.net/MSF.857.305

[20] Ekaputri, Ishida and Maekawa, 2010. Autogeneous Shrinkage of Mortars Made With Different Types of Slag Cement, JCI Annual Conference, Vol.32, No.1, pp.353-358.

[21] Ekaputri, Bongochgetsakul, Ishida and Maekawa, 2009. Internal Relative Humidity Measurement on Moisture Distribution of Mortar Considering Self-Dessication at Early Ages, JCI Annual Conference, vol 31 no 1, pp.643-648.

[22] Nasir, Noor Azline Mohd, Farah N.A. Abd Aziz, and N.A Safiee. 2014. "Hydration of the combinations of ground granulated blast furnace slag cement." Australian Journal of Basic and Applied Sciences (American - Eurasian Network for Scientific Information) 8: 392 - 396.

[23] Fernandez, Raul, Lorena Gonzalez, Ana Isabel Rulz, and Jaime Cuevas. 2014. Nature of C - ( A ) - S - H Phases Formed in the Reaction Bentonite/Portlandite. Journal of Geochemistry.

[24] Oliver, K, A. Darquennes, F. Benboudjema, and R. Gagne. 2013. "Experimental studies of self healing cementious materials incorporating mineral admixtures." Fourth International Conference on Self Healing Materials. Belgium: Ghent University.

[25] Ekaputri J J, Alrizal F F, Husein I, Triwulan and Abdullah M M A B A, 2016. An Application of Rice Husk Ash (RHA) and Calcium Carbonate (CaCO3) as Material for Self-Healing Cement, Key Engineering Materials, Vol. 673 (2016) pp 3-12. 